\title{
Overexpression of Pigment Epithelium-Derived Factor Inhibits Retinal Inflammation and Neovascularization
}

\author{
Kyoungmin Park, ${ }^{*} \mathrm{Ji}$ Jin, ${ }^{\dagger}$ Yang Hu, ${ }^{*}$ Kevin Zhou, ${ }^{*}$ \\ and Jian-xing $\mathrm{Ma}^{*}$ \\ From the Departments of Physiology and Medicine," University of \\ Oklahoma Health Sciences Center, Oklahoma City, Oklaboma; \\ and the Department of Ophthalmology, ${ }^{\dagger}$ Children's Hospital, \\ Zhejiang University, Hangzhou, China
}

Pigment epithelium-derived factor (PEDF) is a serine proteinase inhibitor with antiangiogenic activities. To investigate whether PEDF overexpression has an impact on ocular neovascularization in vivo, we generated PEDF transgenic (PEDF-Tg) mice that ubiquitously express human PEDF driven by the $\beta$-actin promoter. The PEDF-Tg mice under normal conditions did not show any abnormalities in retinal histologic findings or visual function. In contrast, PEDF-Tg animals with oxygen-induced retinopathy (OIR) developed significantly less severe retinal neovascularization compared with wild-type (Wt) mice with OIR. In addition, PEDF-Tg mice with OIR had significantly lower vascular leakage in the retina but higher occludin levels than the Wt mice with OIR, suggesting a protective effect on the bloodretinal barrier. Furthermore, retinal levels of proinflammatory factors were significantly lower in PEDF-Tg mice with OIR than in the Wt mice with OIR. In the laser-induced choroidal neovascularization (CNV) model, the $\mathrm{CNV}$ area was significantly smaller in the PEDF-Tg mice than in the Wt mice. Also, the laser burn-induced overexpression of proangiogenic and inflammatory factors was observed in the retina and retinal pigment epithelium of Wt mice but not in PEDF-Tg mice. Taken together, these results suggest that overexpression of PEDF inhibits retinal inflammation and neovascularization in both the OIR and laser-induced CNV models. The PEDF-Tg mice provide a useful model for studying the roles of angiogenic inhibitors in neovascular disorders such as diabetic retinopathy. (Am J Pathol 2011, 178:688-698; DOI: 10.1016/j.ajpath.2010.10.014)
Pigment epithelium-derived factor (PEDF) is a $50-\mathrm{kDa}$ secreted glycoprotein that belongs to the serine proteinase inhibitor superfamily. ${ }^{1}$ PEDF was originally identified as a neurotrophic factor, inducing neuron differentiation and promoting neuron survival under stress conditions. $^{2,3}$ In addition to its neurotrophic activities, PEDF also inhibits angiogenesis. ${ }^{4}$ In the eye, it has been reported that PEDF functions as a major angiogenic inhibitor in both the retina and vitreous body, counterbalancing the proangiogenic factor vascular endothelial growth factor (VEGF). ${ }^{5}$ Interestingly, PEDF has been shown to be a multifunctional protein because it displays antivasopermeability, ${ }^{6}$ anti-inflammatory, ${ }^{7}$ antifibrosis, ${ }^{8}$ and anticancer $^{9,10}$ activities.

Decreased ocular levels of PEDF have been associated with abnormal angiogenesis in some ocular diseases, such as proliferative diabetic retinopathy and neovascular age-related macular degeneration. ${ }^{11,12}$ It has been suggested that an age-related decline of PEDF in the aqueous humor may account for less PEDF-mediated neurotrophic and antiangiogenic activities, predisposing the aging eye to ocular diseases. ${ }^{13}$ In $d b / d b$ mice, a mouse model of type 2 diabetes mellitus, ${ }^{14}$ lower vitreous levels of PEDF are associated with early-onset diabetic retinopathy. ${ }^{15}$ In the oxygen-induced retinopathy (OIR) model, decreased protein levels of PEDF in the retina are associated with ischemia-induced retinal neovascularization. ${ }^{16}$ Several groups have shown that intravitreal injection of either an adenovirus expressing human PEDF or a purified recombinant PEDF protein inhibited retinal neovascularization in different animal models. ${ }^{17-20}$ Also, a

Supported by National Institutes of Health grants EY018659, EY012231, and EY019309; grant P2ORR024215 from the National Center For Research Resources; by a grant from the Oklahoma Center for the Advancement of Science and Technology; and by a research award from the American Diabetes Association.

Accepted for publication October 21, 2010.

Supplemental material for this article can be found at $h$ ttp://ajp. amjpathol.org or at doi: 10.1016/j.ajpath.2010.10.014.

Address reprint requests to Jian-xing Ma, M.D., Ph.D., University of Oklahoma Health Sciences Center, 941 Stanton L. Young Blvd., BSEB 328B, Oklahoma City, OK 73104. E-mail: jian-xing-ma@ouhsc.edu. 
recent study reported that PEDF knockout mice are more susceptible to OIR-mediated retinal vessel obliteration and excessive VEGF expression under hyperoxic conditions. ${ }^{21}$

To further study the role of PEDF in angiogenesis, we generated a transgenic mouse model that overexpresses PEDF (PEDF-Tg). The effects of high levels of endogenous PEDF on ischemia-induced retinal neovascularization and laser-induced choroidal neovascularization (CNV), as well as its impact on normal retinal vascular development, were studied.

\section{Materials and Methods}

\section{Cell Culture and Treatment}

Human retinal endothelial cells (HRECs) were purchased from Cell Science (Canton, MA) and cultivated as described by the supplier. The cells were used in low passages (up to the fourth passage). Cells were grown on culture dishes precoated with $0.2 \%$ gelatin (Sigma, St. Louis, MO). The cells were exposed to hypoxia and treated with various concentrations of PEDF for 48 hours and then harvested and lysed in RIPA buffer $(150 \mathrm{mmol} / \mathrm{L}$ $\mathrm{NaCl}, 1 \% \mathrm{NP}-40,0.1 \% \mathrm{SDS}, 50 \mathrm{mmol} / \mathrm{L}$ Tris- $\mathrm{HCl}, \mathrm{pH} 8.0$, $1 \mathrm{mmol} / \mathrm{L}$ EDTA, and $1 \mathrm{mmol} / \mathrm{L}$ phenylmethylsulfonyl fluoride). For induction of hypoxia by using $\mathrm{CoCl}_{2}$ (Sigma), HRECs were cultured overnight in 6-well plates and incubated with $200 \mu \mathrm{mol} / \mathrm{L}$ of $\mathrm{CoCl}_{2}$ and different concentrations of PEDF for 4 hours.

\section{Construction of the PEDF Transgene and Generation of the PEDF-Tg Mice}

Care and use of all animals in this study were in strict agreement with the guidelines in the Use of Animals in Ophthalmic and Vision Research and approved by the Institutional Animal Care and Use Committee at the University of Oklahoma. All of the animal experiments were performed in compliance with the Association for Research in Vision and Ophthalmology Statement for the Use of Animals in Ophthalmic and Vision Research. For the generation of PEDF-Tg mice, the full-length coding region of the human PEDF CDNA, driven by the chicken $\beta$-actin promoter and flanked at the $3^{\prime}$ end by a SV40 T-antigen polyadenylation signal, was cloned into the pTriEx-1.1 vector (EMD Chemical, Gibbstown, NJ). Expression of the PEDF transgene was first confirmed in cultured cells, and then the transgene was injected into fertilized C57BL6/J mouse oocytes at the Molecular Biology Core Facility at the Oklahoma Medical Research Foundation (Oklahoma City, OK). Founders were screened by genotyping with PCR using a forward primer specific to the chicken $\beta$-actin promoter (5'-CCGGGACCTTTAATTCAACCCAAC-3') and a reverse primer specific for exon 1 of the PEDF CDNA (5'TCCAATGCAGAGGAGTAGCACCA-3'). The PCR conditions were $95^{\circ} \mathrm{C}$ for 4 minutes, followed by 35 cycles of $95^{\circ} \mathrm{C}$ for 30 seconds, $53^{\circ} \mathrm{C}$ for 30 seconds, and $72^{\circ} \mathrm{C}$ for 40 seconds, and then 1 cycle of $72^{\circ} \mathrm{C}$ for 10 minutes.
Human PEDF expression in the PEDF-Tg mice was verified by Western blot analysis using tail tissue.

\section{Western Blot Analysis}

For ocular samples, free-floating retinas or eyecups were homogenized in $150 \mu \mathrm{L}$ of ice-cold tissue lysis buffer (50 $\mathrm{mmol} / \mathrm{L}$ Tris- $\mathrm{HCl}, \mathrm{pH} 7.8,0.1 \mathrm{M} \mathrm{NaCl}, 5 \mathrm{mmol} / \mathrm{L}$ EDTA, $0.1 \%$ SDS, $0.1 \%$ Triton X-100, 2.5\% glycerol, and 1 $\mathrm{mmol} / \mathrm{L}$ phenylmethylsulfonyl fluoride). The homogenates were cleared by centrifugation at $12,000 \times g$ for 20 minutes at $4^{\circ} \mathrm{C}$, and then the protein concentration of the lysates was determined using the Bradford assay. Equal amounts of retinal or eyecup proteins from each mouse or cell lysates were resolved by SDS-polyacrylamide gel electrophoresis using $8 \%$ to $12 \%$ denaturing gels and transferred onto nitrocellulose membranes. Immunoblotting and signal detection by electrochemoluminescence (Pierce, Rockford, IL) were performed as described previously. ${ }^{22}$ The primary antibodies were used at the following dilutions: polyclonal anti-PEDF antibody (Upstate, Billerica, MA) at 1:2000, rabbit anti-VEGF antibody (Santa Cruz Biotechnology, Santa Cruz, CA) at 1:1000, goat anti-intercellular adhesion molecule 1 (ICAM-1) antibody (Santa Cruz Biotechnology) at 1:4000, goat anti-connective tissue growth factor (CTGF) antibody (Santa Cruz Biotechnology) at 1:1000, rabbit antioccludin antibody (Abcam, Cambridge, MA) at 1:2000, goat antialbumin antibody (Bethyl, Montgomery, TX) at 1:1000, a goat antiICAM-1 antibody at 1:500 (Santa Cruz Biotechnology), and mouse anti- $\beta$-actin (Abcam) at 1:2000. Antibody dilutions were made in a solution of $5 \%$ nonfat milk powder/ Tris-buffered saline Tween-20 (0.1\%). The signal intensity was quantified with a densitometer (GeneTool software; SynGene, Frederick, MD).

For measurement of PEDF levels, plasma and various tissues were collected from 4 PEDF-Tg and 4 agematched wild-type $(\mathrm{Wt})$ mice. PEDF levels in the plasma were determined by Western blot analysis using $40 \mu \mathrm{g}$ of proteins and the anti-PEDF antibody (Upstate, Billerica, MA). Ponceau S staining (Sigma) was performed to verify equal protein loading. For tissue lysates, sliced tissues were homogenized in $250 \mu \mathrm{L}$ of the ice-cold tissue lysis buffer. The homogenates were cleared by centrifugation at $12,000 \times g$ for 20 minutes at $4^{\circ} \mathrm{C}$, and the protein concentration of the supernatant was determined using the Bradford assay. The soluble proteins from the tissues were subjected to Western blot analysis.

\section{Retinal Histology and Immunofluorescence Staining}

Four-month-old PEDF-Tg and Wt control mice were anesthetized and perfused transcardially with PBS. The eyes were immersion fixed in $4 \%$ paraformaldehyde for 2 hours and stored in $75 \%$ ethanol. After fixation, the eyes were embedded and cross-sectioned vertically through the center of the cornea and optic nerve.

For histologic analyses, ocular and retinal structures were analyzed on 5- $\mu \mathrm{m} \mathrm{H \& E-stained} \mathrm{sections} \mathrm{following} \mathrm{a}$ 
documented protocol. ${ }^{22}$ Digitized images were captured using a CKK41 digital imaging system (Olympus America, Center Valley, PA) at 20× magnification.

Immunofluorescence staining was performed as described previously. ${ }^{22}$ In brief, deparaffinized and rehydrated ocular sections were exposed to hydrogen peroxide to eliminate endogenous peroxide activity. The sections were then permeabilized for 30 minutes using PBS/0.4\% Triton X-100 followed by blocking in PBS/3\% $\mathrm{BSA} / 10 \%$ goat serum for 30 minutes. After $3 \times 10 \mathrm{~min}$ utes washes with PBS, the sections were incubated with a rabbit polyclonal antibody to PEDF (diluted 1:250 in PBS; Upstate) for 2 hours at $4^{\circ} \mathrm{C}$. The sections were then rinsed in PBS/0.2\% Triton X-100 and incubated with a Cy5-conjugated anti-rabbit IgG (diluted 1:500; Jackson Immunoresearch Lab. Inc, West Grove, PA) for 1 hour. The stained sections were rinsed again and mounted in a mounting medium containing DAPI. The slides were viewed with a CKK41 fluorescence microscope.

\section{Electroretinogram Recordings}

For scotopic electroretinograms (ERGs), 2-month-old PEDF-Tg and Wt mice were dark-adapted overnight before ERG recording. The mice were anesthetized, and the pupils dilated with topical application of 2.5\% phenylephrine and $1 \%$ tropicamide (Sigma). The ERG responses were recorded with a silver chloride needle electrode placed on the surface of the cornea after topical application of $1 \%$ tetracaine anesthesia (Sigma). A reference electrode was positioned at the nasal fornix and a ground electrode on the tail. The ERG system consisted of a Ganzfeld bowl, a DC amplifier, a computer-based control, and a recording unit. ${ }^{22}$ The ERG responses were recorded from both eyes simultaneously after the mice were placed in the Ganzfeld bowl and exposed to a 10-millisecond light stimulus. The bandpass filter cutoff frequencies were 0.3 and $500 \mathrm{~Hz}$ for single-flash or flicker-stimulus recordings, respectively. Single-flash responses were recorded under both dark-adapted (scotopic) and light-adapted (photopic) conditions. Fourteen scotopic responses were recorded and averaged, with flash intervals of 20 milliseconds. Immediately after scotopic ERGs, mice were exposed to a background light of 60 candela $\mathrm{m}^{-2}$ for 10 minutes. Photopic ERGs were then recorded by averaging the responses to 14 single flashes. For quantitative analysis, the B-wave amplitude was measured from the A-wave trough to the B-wave peak.

\section{Mouse Model of OIR}

C57BL/6 mice from the Jackson Laboratory (Bar Harbor, $\mathrm{ME}$ ) and PEDF-Tg mice were used for the OIR model following an established protocol. ${ }^{23} \mathrm{Wt}$ and PEDF-Tg mice (along with their nursing mothers) were exposed to $75 \%$ oxygen from postnatal days 7 to 12 in a Plexiglass chamber connected to an oxygen regulator (Pro-Ox, model 110; Reming Bioinstruments, Redfield, NY). At postnatal day 12 , the animals were returned to room air.
The mice were sacrificed at postnatal day 16 for Western blot analysis or sacrificed at postnatal day 12 for nonperfusion area measurement and at postnatal day 18 for retinal neovascularization examination.

\section{Fluorescein Retinal Angiography and Quantification of Preretinal Vascular Cells}

Retinal angiography was performed as previously described. ${ }^{22,23}$ Briefly, mice were anesthetized and perfused via ventricle with $50-\mathrm{mg} / \mathrm{ml}$ high-molecular-weight $\left(2 \times 10^{6}\right)$ fluorescein isothiocyanate-dextran (Sigma). The mice were immediately sacrificed, and the eyes enucleated and fixed in $4 \%$ paraformaldehyde for 3 hours. The retina was flatmounted on a gelatin-coated slide. The avascular area was measured in the retina using SPOT software (Diagnostic Instruments, Sterling Heights, MI).

For quantification of preretinal vascular cells, the mouse eyes were fixed, sectioned, and stained with H\&E as described previously. ${ }^{22}$ The preretinal vascular nuclei were counted in 8 discontinuous sections per eye and compared between the PEDF-Tg and Wt mice with OIR using Student's $t$-test.

\section{Laser-Induced CNV}

All mice were used for the CNV model following an established protocol. ${ }^{24}$ Laser-induced CNV reflects the pathology of inflammation-related CNV seen in AMD. CNV in the PEDF-Tg and Wt mice was induced by laser photocoagulation. ${ }^{24,25}$ Briefly, 2-month-old Wt and PEDF-Tg mice were anesthetized with ketamine $(100 \mathrm{mg} / \mathrm{kg})$ and xylazine $(10 \mathrm{mg} / \mathrm{kg})$ and their pupils dilated with $1 \%$ tropicamide. For generating laser burns, a red diode laser (810-nm wavelength; Keeler Multilase 1500, Windsor, England, and Iris Medical Oculight SLX, Mountain View, CA) was used under a Fison indirect ophthalmoscope for Genesis-Df fluorescein angiography (Kowa Optimed, Inc, Japan) to induce CNV by rupturing Bruch's membrane. Laser parameters were set to a $150-\mu \mathrm{m}$ spot size, 100millisecond exposure time, and 275-mW power. A series of four laser lesions was placed around the optic discs of both eyes. Only the eyes with visible bubble formations were included in the study. CNV was monitored using funduscope and analyzed in the flat-mounted retinal pigment epithelium (RPE)-choroid complex. Images were captured with an Olympus (Center Valley, PA) CKX41 digital still camera, and image analysis SPOT software (Diagnostic Instruments) was used to measure the total area of CNV.

\section{Real-Time RT-PCR}

Total RNA was extracted from eyecups using TRIzol reagent (Invitrogen, Carlsbad, CA). The cDNA was synthesized from $1 \mu \mathrm{g}$ of total RNA using TaqMan reverse transcription reagents according to the manufacturer's protocol (Applied Biosystems, Foster City, CA), and the reaction product was subjected to PCR amplification using a MyiQ Bio-Rad thermal cycler (Bio-Rad, Hercules, CA). The following primers were used for the PCR: for 
A

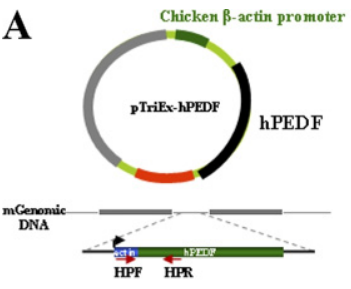

C

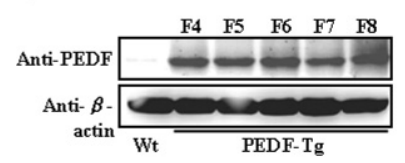

B

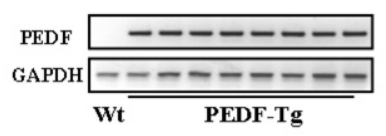

D

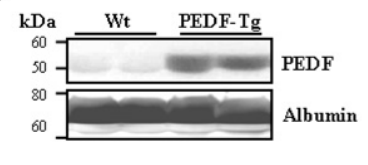

E

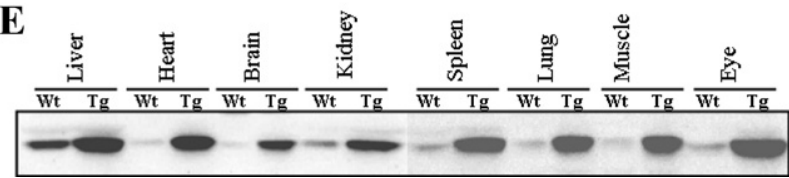

Figure 1. Generation of the PEDF-tg mice. A: Diagram of the human PEDF transgene. B: Genotyping of Wt $(n=11)$ and individual PEDF-Tg mice $(n=$ 12). Each lane represents an individual mouse. C: Western blot analysis to confirm overexpression of PEDF. The same amounts of ear protein $(50 \mu \mathrm{g})$ from F4 to F8 generations of PEDF-Tg and Wt mice were blotted with an anti-PEDF antibody and with $\beta$-actin as a loading control. D: High PEDF levels in the serum of PEDF-Tg mice. Total serum proteins $(40 \mu \mathrm{g})$ from each mouse were analyzed by Western blot analysis using a PEDF-specific antibody and reblotted with an antialbumin antibody. The blot shows results from two representative Wt and PEDF-Tg mice. E: Western blot analysis of PEDF in various tissues from Wt and PEDF-Tg mice. Equal amounts of total proteins from each tissue were blotted with the anti-PEDF antibody.

VEGF, 5'-ATGAACTTTCTGCTGTCTTGGGTG-3' (forward) and 5'-TCACCGCCTCGGCTTGTCACA-3' (reverse); for CTGF, 5'-GTTGTTCATTAGCGCACAGTG-3' (forward) and 5'-TAGAGCAGGTCTGTCAAGCAT-3' (reverse); for ICAM-1, 5'-TGCGTTTTGGAGCTAGCGGACCA-3' (forward) and 5'-CGAGGACCATACAGCACGTGCCAG-3' (reverse); for tumor necrosis factor- $\alpha$ (TNF- $\alpha$ ), 5'ACAAGGCTGCCCCGACTAT-3' and 5'-CTCCTGGTATGAAGTGGCAAATC-3' (reverse); for transforming growth factor- $\beta$ (TGF- $\beta$ ), 5'-AAACGGAAGCGCATCGAA-3' (forward) and 5'-GGGACTGGCGAGCCCTTAGTT-3' (reverse); for monocyte chemotactic protein-1 (MCP-1), 5'-TGGCAAGATGATCCCAATGA-3' (forward) and 5'-GCAGCACTGTTCGTCACTTCA-3' (reverse); and for glyceraldehyde-3-phosphate dehydrogenase, 5'ATGGTGAAGGTCGGTGTGAAC-3' (forward) and 5'-GTGCCGTTGAATTTGCCGTGA-3' (reverse).

\section{Statistical Analysis}

Student's t-test (two-tailed) was used for all of the statistical analysis. Statistical difference was considered significant at $P<0.05$.

\section{Results}

\section{Generation of Transgenic Mice That Overexpress PEDF Ubiquitously}

The chicken $\beta$-actin promoter is commonly used for driving ubiquitous transgene expression in transgenic

mice. ${ }^{26,27}$ In this study, the PEDF transgene contained the human full-length PEDF cDNA under the control of the chicken $\beta$-actin promoter (Figure 1A). PCR of PEDF-Tg genomic DNA identified the PEDF transgene in four independent lines (Figure 1B). As shown by Western blot analysis, PEDF was stably overexpressed in PEDF-Tg mice in all of the eight generations analyzed (Figure 1C). Furthermore, Western blot analysis of the serum from PEDF-Tg mice showed substantially higher circulating PEDF levels than in age-matched $\mathrm{Wt}$ mice (Figure 1D). Similarly, compared with the $\mathrm{Wt}$ mice, PEDF-Tg mice showed substantially higher PEDF levels in all of the tissues analyzed, including the liver, heart, brain, spleen, lung, skeletal muscle, and eye (Figure 1E). Taken together, these results demonstrated that PEDF is ubiquitously and stably expressed in PEDF-Tg mice.

\section{Overexpression of the PEDF Transgene in the Retina of PEDF-Tg Mice}

To determine whether the PEDF transgene is expressed in the retina of PEDF-Tg mice, the retinal homogenates from 4-month-old Wt and PEDF-Tg mice were examined. Western blot analysis showed that PEDF levels were substantially higher in the PEDF-Tg mouse retina than in the Wt mouse retina (Figure 2A). Furthermore, immunostaining of retinal sections revealed PEDF signals in all of the retinal layers of the PEDF-Tg mice, with an intense signal in the inner retina (Figure $2 \mathrm{~B}$ ). Compared with the $\mathrm{Wt}$ retina, PEDF expression levels were higher in all of the retinal layers of PEDF-Tg mice.

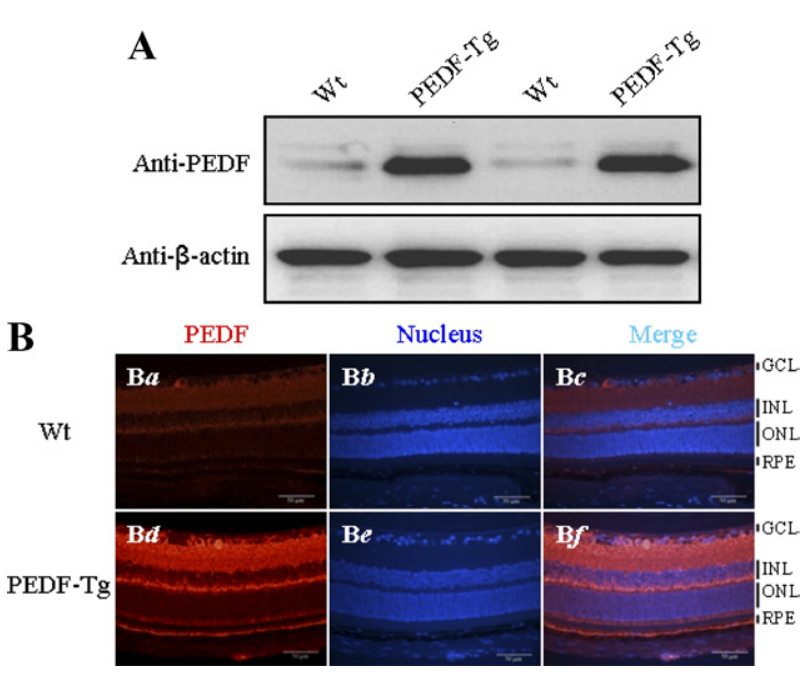

Figure 2. Overexpression of PEDF in the retina of PEDF-Tg mice. A: The same amount of retinal proteins $(50 \mu \mathrm{g})$ from each mouse was blotted sequentially with the anti-PEDF and anti- $\beta$-actin antibodies. The blot shows results from two representative Wt and PEDF-Tg mice $(n=8)$. B: Immunohistochemical analysis of the PEDF-Tg retina. Retinas obtained from Wt and PEDF-Tg mice were immunostained with an antibody for PEDF ( $\mathrm{B} a$ and $\mathrm{B} d$ ), and the nuclei were counterstained with DAPI $(\mathrm{B} b$ and $\mathrm{B} e)$. The images are representatives from two independent experiments in Wt and PEDF-Tg mice $(n=8)$. GCL, ganglion cell layer; INL, inner nuclear layer; ONL, outer nuclear layer; RPE, retinal pigment epithelium 


\section{Histologic Structure of the Retina and Visual Function of PEDF-Tg Mice}

To determine whether PEDF overexpression in the retina affects ocular and retinal structure, ocular sections from Wt and PEDF-Tg mice were examined histologically. At 4 months of age, there was no detectable difference in the ocular structure or the nuclear layers of the retina between Wt and PEDF-Tg mice (Figure 3, $A$ and $B$ ). Furthermore, the visual function of the PEDF-Tg mice was evaluated by ERG recording. Analysis of the dark-adapted (scotopic or rod-associated) and light-adapted (photopic or cone-associated) ERG waveforms revealed that there was not a significant difference in the retinal function between $\mathrm{Wt}$ and PEDF-Tg mice (Figure 3, C and D; $P>0.05$ ). Taken together, these results suggest that PEDF-Tg mice do not have structural or functional defects in the retina under normal conditions.

\section{Effects of PEDF Overexpression on Ischemia-Induced Retinal Neovascularization}

The impact of PEDF overexpression on ischemia-induced retinal neovascularization was evaluated in the OIR model, which develops ischemia-induced retinal neovascularization. ${ }^{23}$ After exposure to $75 \%$ oxygen from postnatal day 7 to 12 , the retinal vasculature of the PEDF-Tg and Wt mice with OIR was examined at post-
A
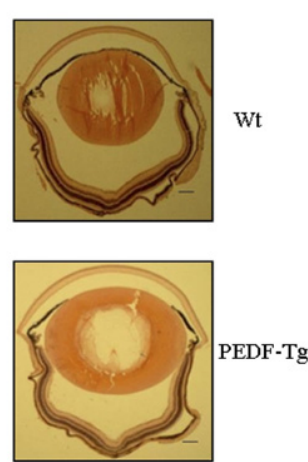

C

Cone

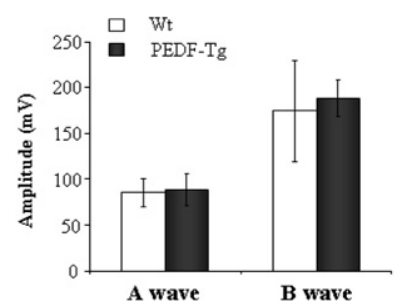

B
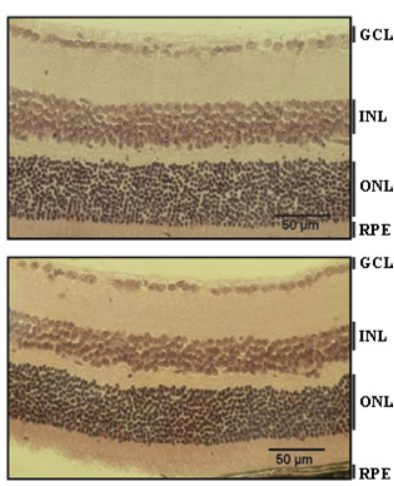

D

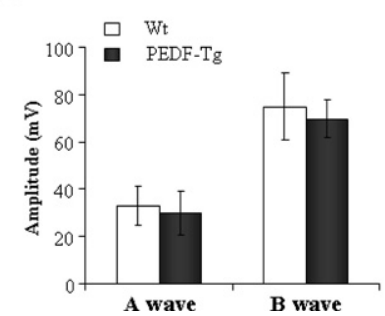

Figure 3. The ocular and retinal structure and visual function of Wt and PEDF-Tg mice. A and B: The H\&E-stained eye sections from 8-week-old Wt and PEDF-Tg mice. A: Ocular sections, $4 \times$; scale bars $=200 \mu \mathrm{m}$. B: Retinal structure, $20 \times$. The images were representatives from five mice of each type. C and D: ERG amplitudes of Wt and PEDF-Tg mice. Dark-adapted (scotopic/ rod-associated) and light-adapted (photopic/cone-associated) ERGs were recorded from Wt and PEDF-Tg mice and the amplitudes of the $\mathrm{A}$ and $\mathrm{B}$ waves compared (mean $\pm \mathrm{SD}, n=6$ ). GCL, ganglion cell layer; INL, inner nuclear layer; ONL, outer nuclear layer; RPE, retinal pigment epithelium.
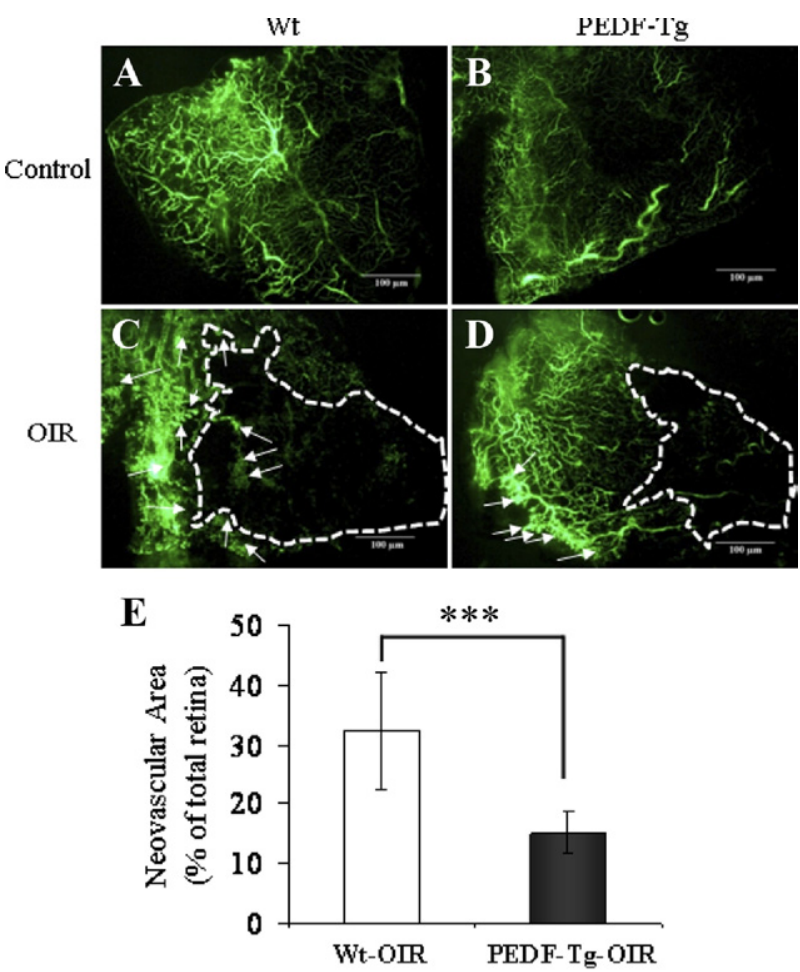

Figure 4. The inhibitory effect of PEDF overexpression on retinal neovascularization in the OIR model. PEDF-Tg and Wt mice were exposed to $75 \%$ oxygen from postnatal day 7 to 12 . The Wt and PEDF-Tg mice with OIR were perfused with fluorescein-dextran at postnatal day 18 and the retina flat mounted. A-D: Representative retinal angiographs from the eyes of Wt and PEDF-Tg mice with OIR (C and $\mathbf{D})$ and Wt and PEDF-Tg mice in the room air (A and $\mathbf{B}$ ) as a control. $\mathbf{C}$ and $\mathbf{D}$ : The white arrows indicate neovascular tufts in the peripheral retina. The white dotted line represents avascular area in the central retina. All of the images were from the peripheral retina (no optic nerve included). E: Quantification of the neovascularization in the retinas from Wt and PEDF-Tg mice with OIR. Retinal neovascularization was semiquantified by measuring the ratio of the neovascular tuft area to the total retinal area using the advanced SPOT software (mean $\pm \mathrm{SD}, n=8$, $\left.{ }^{\text {****** }} P<0.001\right)$.

natal day 18. To determine whether overexpression of PEDF suppresses the ischemia-induced retinal neovascularization, we examined the retinal vasculature using fluorescein angiography in retinal flat mounts. The results revealed significant neovascularization in the flat-mounted retina of Wt mice with OIR at postnatal day 18 (Figure 4C). In contrast, the retina in PEDF-Tg mice with OIR developed less severe neovascular tufts in the perfusion area at the same age (Figure 4D). Normal control PEDF-Tg and Wt mice maintained in constant room air had no apparent difference in retinal vasculature (Figure 4, A and B). The retinal neovascularization was quantified by measuring areas of neovascular tufts in retinal whole mounts, which showed that the retinas from PEDF-Tg mice with OIR have significantly smaller retinal neovascular areas, approximately $47 \%$ of those in Wt mice with OIR (Figure 4E). To further determine the extent of vessel obliteration in the early phase of OIR, ${ }^{28,29}$ we measured the nonperfused areas in the central retina at postnatal day 12 , which has been shown to correlate with the severity of retinopathy in the OIR model. ${ }^{23}$ In the PEDF-Tg mice with OIR, the nonperfusion area was significantly 
smaller than that in Wt mice with OIR (see Supplemental Figure S1 at http://ajp.amjpathol.org). Taken together, these results suggest that PEDF overexpression ameliorates hyperoxia-mediated vessel lost and ischemia-induced retinal neovascularization.

\section{Reduced Preretinal Neovascularization in PEDF-Tg Mice With OIR}

To further confirm the effect of PEDF overexpression on retinal neovascularization, we quantified preretinal neovascular cells, a characteristic feature of the OIR model and human proliferative diabetic retinopathy. ${ }^{23,30,31}$ The preretinal neovascular cells growing into the vitreous space were counted on eight noncontinuous cross-sections from each eye following an established method. ${ }^{22,23}$ As shown in Figure 5, the number of preretinal neovascular cells in the retina of PEDF-Tg mice with OIR $(n=13)$ was approximately twofold lower than that in the retina of Wt mice with OIR $(P<0.05, n=13)$, confirming the antineovascularization effect of PEDF overexpression in the retina.

\section{Effect of PEDF Overexpression on Ischemia-Induced Retinal Inflammation and Vascular Leakage}

Previous studies have shown that the blood-retinal barrier (BRB) breakdown and inflammation are important features of OIR and human diabetic retinopathy. ${ }^{32,33}$ To
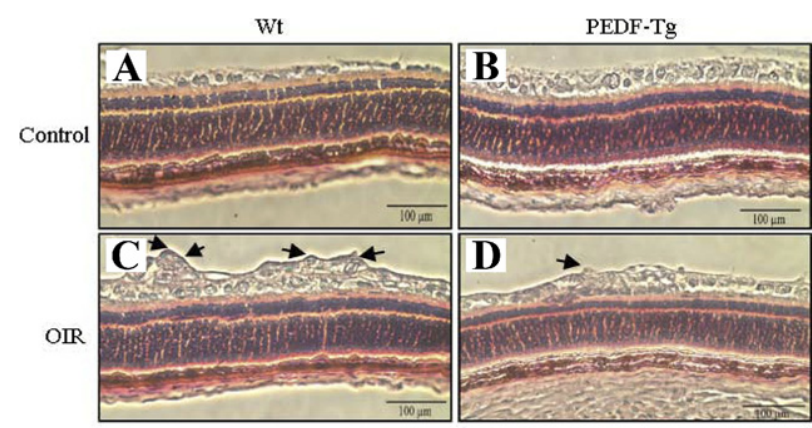

$\mathbf{E}$

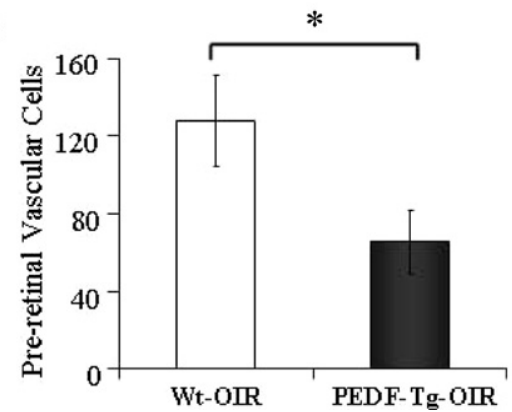

Figure 5. The effect of PEDF overexpression on preretinal neovascularization in mice with OIR. At postnatal day 18, the eyes of PEDF-Tg and Wt mice with OIR were fixed, sectioned, and stained with H\&E. A-D: Preretinal vascular cells were counted in eight noncontinuous sections per eye and averaged. A: Representative retinal sections from Wt mice under normoxia. B: PEDF-Tg mice under normoxia. C: Wt mice with OIR. D: PEDF-Tg mice with OIR. Arrows indicate preretinal vascular cells. E: The average numbers of preretinal vascular cells (mean $\pm \mathrm{SD}, n=13$ ) were compared between the eyes from Wt and PEDF-Tg mice with OIR using Student's $t$-test. ${ }^{*} P<0.05$
A
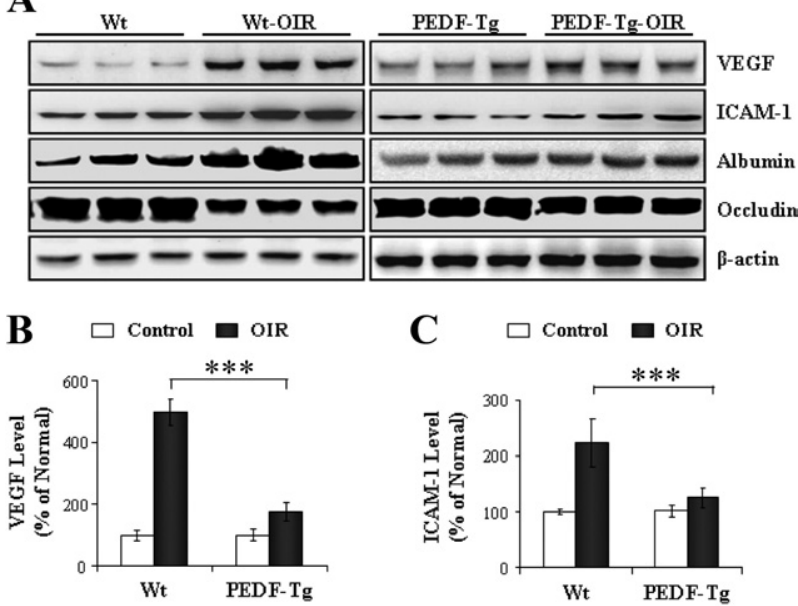

C $\square$ Control $\square$ OIR

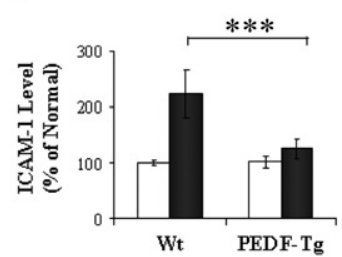

D

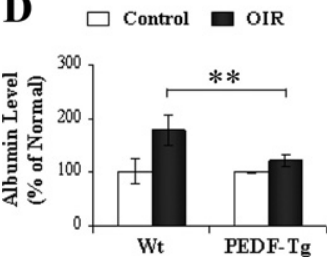

$\mathbf{E}$

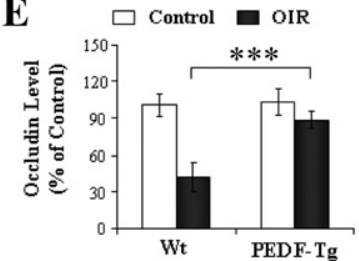

Figure 6. The effects of PEDF overexpression on retinal levels of VEGF, ICAM-1, albumin, and occludin in OIR mice. PEDF-Tg and Wt mice were exposed to $75 \%$ oxygen from postnatal day 7 to 12 . Another group of Wt and PEDF-Tg mice were maintained in constant room air as normoxic controls. At postnatal day 16, the mice were euthanized, perfused, and total retinal protein isolated. A: Retinal levels of VEGF, ICAM-1, albumin, occludin, and $\beta$-actin were measured by Western blot analysis. B-E: The expression levels of each protein were quantified by densitometry, normalized to $\beta$-actin levels, and expressed as percentages of the respective normoxic control (mean $\left.\pm \mathrm{SD}, n=3,{ }^{* * *} P<0.01,{ }^{* * * * *} P<0.001\right)$.

examine the PEDF-Tg retina for inflammation, the retinal levels of inflammatory factors in the retinas of Wt mice and PEDF-Tg with OIR were compared. Retinal levels of VEGF, a major angiogenic, permeability, and inflammatory factor, were elevated 5.4 -fold in the retinas of $\mathrm{Wt}$ mice with OIR over those in normal Wt mice maintained under constant room air (Figure 6, A and B). In contrast, the retinas in PEDF-Tg mice with OIR showed significantly less VEGF overexpression (less than twofold over room air control), compared with the retina of Wt mice with OIR. Likewise, Western blot analysis showed that ICAM-1, which can cause leukocyte adhesion in diabetic retinopathy, was significantly up-regulated in the retina of Wt mice with OIR but not in the retina of PEDF-Tg mice with OIR (Figure 6, A and C). As an indicator of retinal vascular leakage and BRB breakdown, retinal albumin levels (after perfusion to remove the blood in the retinal vasculature) were increased in the Wt mice with OIR but not in the PEDF-Tg mice with OIR (Figure 6, A and D). This result suggests that vascular leakage in the OIR model was attenuated by PEDF overexpression. Consistent with retinal vascular leakage, levels of occludin, one of the tight junction proteins, were decreased in the retina of Wt mice with OIR (Figure 6, A and E). In the retina of PEDF-Tg mice with OIR, however, the decrease in occludin levels was largely attenuated, suggesting a PEDF-mediated protective effect on the BRB (Figure 6, $A$ and $E$ ). 

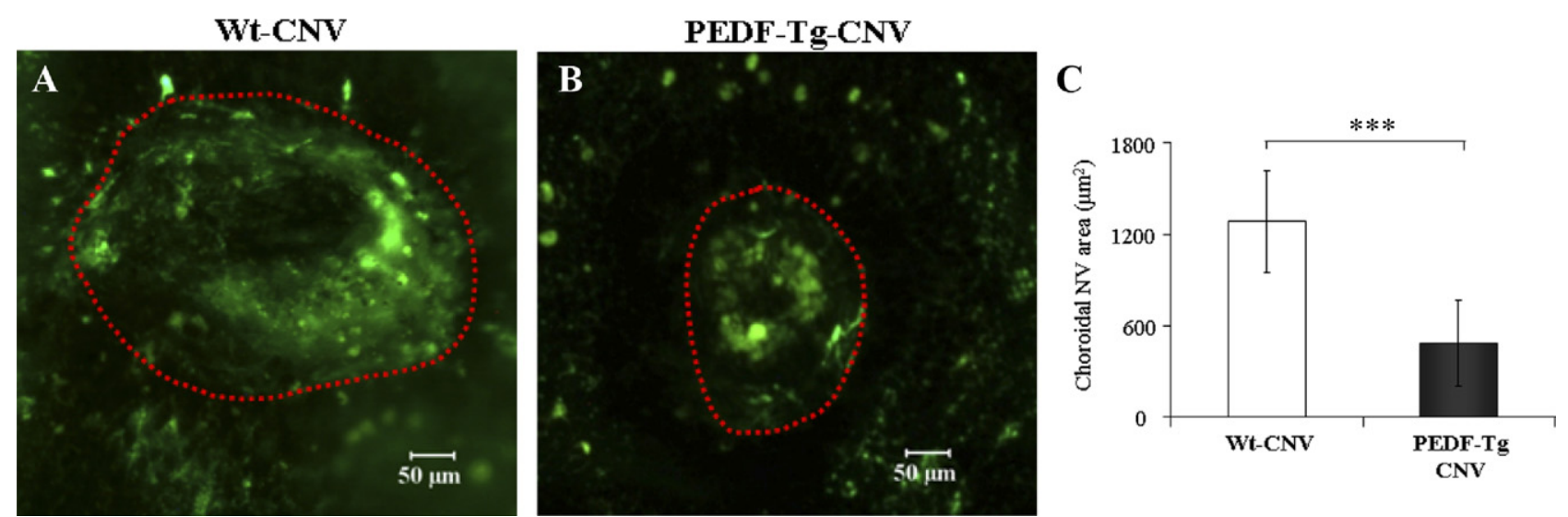

Figure 7. An inhibitory effect of PEDF overexpression on laser-induced CNV. Adult Wt and PEDF-Tg mice were used for laser-induced CNV, and the CNV was visualized by fluorescein angiography 2 weeks after the laser burn. A and B: Representative fluorescein angiographs showing CNV in the flat-mounted retina-choroid complex from Wt mice $(\mathbf{A})(n=7)$ and PEDF-Tg mice $(\mathbf{B})(n=6)$. C: Areas of CNV were measured with the SPOT software and compared between $\mathrm{Wt}$ and PEDF-Tg mice (mean $\pm \mathrm{SD}, n=6,{ }^{* * * *} P<0.001$ ).

\section{PEDF Overexpression Inhibits Laser-Induced CNV}

Laser-induced CNV is a commonly used model for wet AMD because it develops subretinal neovascularization. ${ }^{34,35}$ As shown by angiography on retina-choroidal flat mounts 2 weeks after laser burn, Wt mice with CNV developed apparently larger CNV lesions compared with the PEDF-Tg mice with CNV (Figure 7, A and B). Furthermore, the mean area of laser-induced CNV was significantly smaller in the PEDF-Tg mice with CNV than in the Wt controls with CNV $(P<0.01$, Figure $7 \mathrm{C})$.

\section{Overexpression of PEDF Suppresses Overproduction of Proangiogenic and Inflammatory Factors in the Laser-Induced CNV Model}

Laser-induced CNV is associated with the overproduction of angiogenic, inflammatory, and fibrogenic factors in the retina and RPE. ${ }^{36-41}$ To investigate the inhibitory mechanism of PEDF overexpression on CNV, we compared the expression levels of representative angiogenic, inflammatory, and fibrogenic factors. As shown by Western blot analysis, protein levels of VEGF, CTGF, ICAM-1, and TGF- $\beta$ were significantly increased in the retina and RPE of Wt mice with CNV compared with those in normal mice (Figure 8A). However, levels of these proteins were not increased in the retinas of PEDF-Tg mice with CNV and RPE (Figure 8A). Moreover, real-time PCR showed that mRNA levels of VEGF, ICAM-1, MCP-1, TGF- $\beta$, TNF- $\alpha$, and CTGF were significantly lower in the retina and RPE of the PEDF-Tg mice with CNV compared with the Wt mice with CNV (Figure 8, B-G). Taken together, these results suggest that PEDF overexpression has an inhibitory effect on CNV, inflammation, and fibrosis in the laser-induced CNV model.

\section{Discussion}

PEDF is believed to be a major angiogenic inhibitor in the eye. ${ }^{4}$ Previous studies showed that PEDF levels are decreased in the vitreous of diabetic retinopathy patients, ${ }^{42}$ in the aging aqueous humor and choroid, ${ }^{13}$ and in the eyes of patients with AMD. ${ }^{43}$ Furthermore, $d b / d b$ mice and OIR rats showed decreased levels of PEDF in the retina. ${ }^{11,15}$ These findings suggest that decreased PEDF levels may contribute to a disturbed balance in angiogenic control in the eye, leading to ocular neovascularization.

It has been reported that intravitreal gene delivery of PEDF suppresses retinal and choroidal neovascularization. ${ }^{17,44}$ In addition, purified recombinant PEDF suppressed retinal neovascularization after OIR. ${ }^{18,45}$ The present study presents the first evidence suggesting that overexpression of a PEDF transgene in the retina attenuates ischemia-induced retinal neovascularization and laser-induced CNV. Moreover, PEDF overexpression ameliorates retinal inflammation and vascular leakage. These observations indicate that PEDF functions as both an antiangiogenic and anti-inflammatory factor in the retina.

To evaluate the in vivo effect of PEDF overexpression on ocular neovascularization, we established a transgenic mouse model that ubiquitously overexpresses PEDF (Figures 1 and 2). Under normoxic conditions, the PEDF-Tg retina displayed no overt behavioral or developmental abnormalities (Figure 3). Furthermore, overexpression of PEDF in the retina did not affect retinal structure and function, suggesting that high levels of PEDF do not affect normal vascular development. However, under pathogenic conditions, overexpression of PEDF attenuated pathological neovascularization. The mechanism(s) for these differential effects of PEDF on normal vascular formation and pathological neovascularization remains to be investigated.

OIR is a commonly used model of ischemia-induced retinal neovascularization. ${ }^{23,30}$ Previous studies showed that this model has decreased PEDF levels and increased VEGF levels at postnatal day 16, leading to the 
A

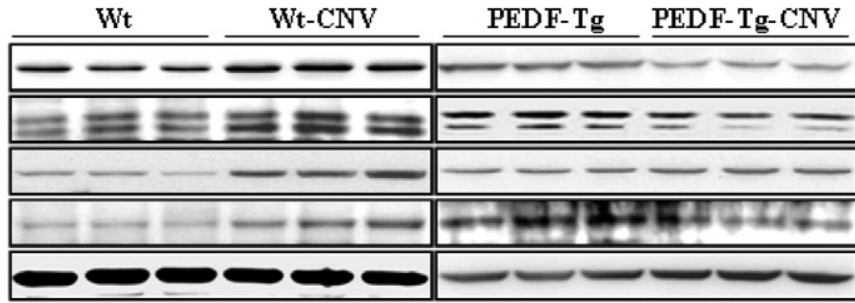

VEGF

CTGF

TGF- $\beta$

ICAM-1

p-actin
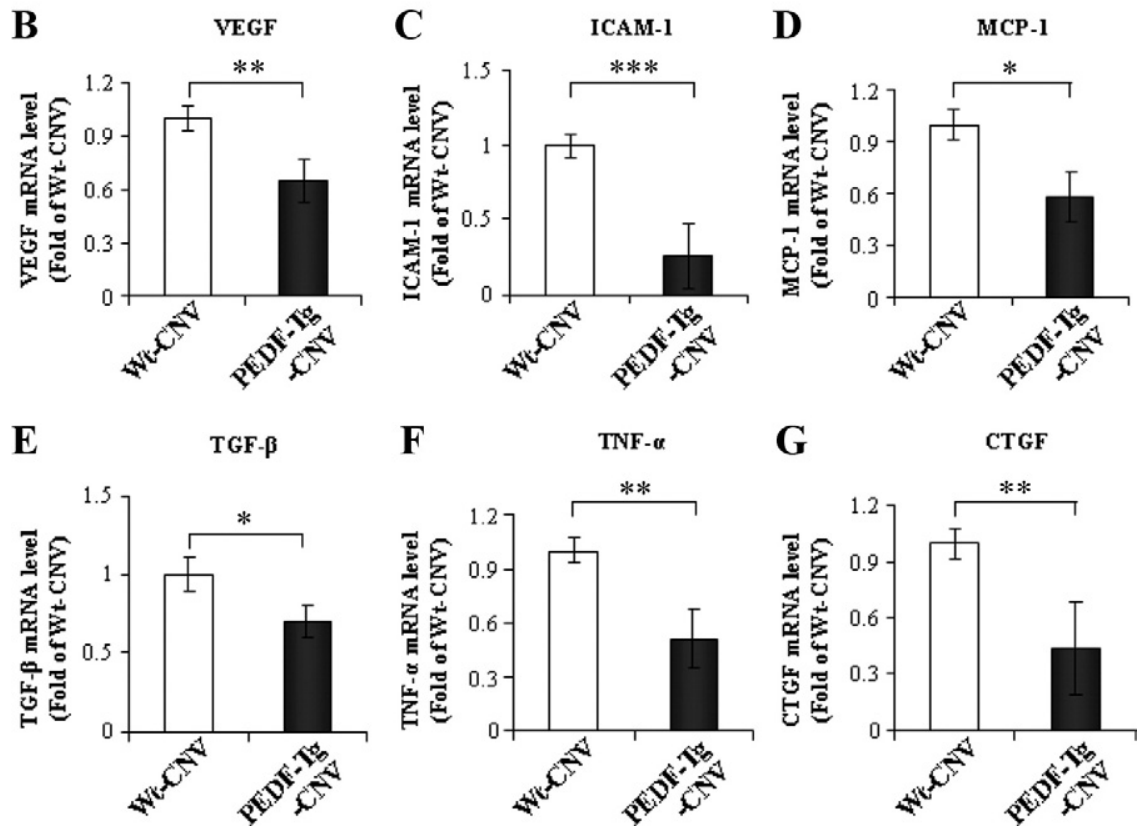

Figure 8. Overexpression of PEDF prevented the overexpression of angiogenic, inflammatory, and fibrogenic factors in the laser-induced CNV model. Two weeks after laser burn, PEDF-Tg and Wt mice with CNV were perfused thoroughly. The same amount of protein from the retina and RPE was used for Western blot analysis of VEGF, CTGF, TGF- $\beta$, ICAM- 1 , and $\beta$-actin. A: Representative blots of VEGF, CTGF, TGF- $\beta$, and ICAM- 1 levels from the Wt mice, Wt mice with CNV, PEDF-Tg mice, and PEDF-Tg mice with CNV. Each lane represents a single mouse. The blots are representatives from three independent experiments. B-G: Real-time RT-PCR analysis of VEGF, ICAM-1, MCP-1, TGF- $\beta$, TNF- $\alpha$, and CTGF mRNA levels in the retina and RPE of Wt and PEDF-Tg mice with CNV (mean \pm $\left.\mathrm{SD}, n=7,{ }^{*} P<0.05,{ }^{* *} P<0.01,{ }^{* * * *} P<0.001\right)$.

disturbed balance between VEGF and PEDF. The increased VEGF:PEDF ratio correlates with retinal neovascularization. ${ }^{46,47}$ To evaluate the effect of PEDF overexpression on retinal neovascularization in the OIR mouse model, we used fluorescein angiography on retinal whole mounts. The results showed that the ischemia-mediated neovascularization, as quantified by both neovascular tufts and preretinal vascular cells, is suppressed in the PEDF-Tg mice with OIR compared with that in the $\mathrm{Wt}$ mice with OIR. This observation supports our previous notion that decreased PEDF levels contribute to retinal neovascularization in the OIR model. ${ }^{11-13,15,16}$

In the laser-induced CNV model, it was shown that CNV represents a wound healing response. ${ }^{48,49}$ Previous studies have reported a significant decrease in PEDF immunoreactivity in the choroid from AMD human donors and rats with laser-induced CNV. ${ }^{12,43,50}$ Interestingly, periocular injection of a PEDF-expressing adenovirus has been shown to suppress laser-induced CNV. ${ }^{51}$ Furthermore, intravitreal injection of the adenovirus expressing PEDF regresses CNV in VEGF transgenic mice overexpressing VEGF in photoreceptors driven by the rhodopsin promoter (Rho/VEGF), which is a well-characterized model in which neovascularization sprouts from the deep capillary bed of the retina and invades the photoreceptor layer and subretinal space. ${ }^{17,20,52}$ Our results showed that endogenous overexpression of PEDF in the retina results in a significantly decreased CNV area compared with Wt mice. This observation suggests that PEDF overexpression blocks not only neovascularization in the OIR model but also CNV induced by laser burn.

Breakdown of the BRB and vascular leakage are suggested to play a causative role in diabetic macular edema, the most common cause of vision loss in diabetic patients. ${ }^{53-55}$ Several studies have shown that PEDF is a major angiogenic inhibitor in the eye and counterbalances the proangiogenic and inflammatory factor, VEGF. Previous evidence suggests that a disturbed balance between VEGF and PEDF levels is associated with those neovascular conditions in the eye of diabetic retinopathy. ${ }^{56,57}$ Therefore, VEGF has been widely recognized as a major pathogenic factor in the BRB breakdown. ${ }^{53,58,59}$ Previous studies have shown that injection of PEDF protein or adeno-associated virus expressing the PEDF gene reduces vascular leakage in the retina of streptozotocininduced diabetic retinopathy or ischemia-induced retinopathy. ${ }^{7,19}$ Our results demonstrated that PEDF overexpression significantly reduces leakage of albumin into the 
retina in both the OIR (Figure 6) and laser-induced CNV models (data not shown). The BRB in the inner retina resides on the tight junction between endothelial cells; down-regulation of tight junction proteins is known to contribute to retinal vascular leakage. Our results showed that PEDF overexpression in PEDF-Tg mice or in HRECs (see Supplemental Figure S2B at http://ajp.amjpathol.org) is associated with the down-regulation of a tight junction protein induced by ischemia using the $\mathrm{CoCl}_{2}$, possibly contributing to its inhibitory effect on vascular leakage. Taken together, these results suggest a protective effect of PEDF on the BRB.

Inflammation is an important pathological feature in both diabetic retinopathy and AMD. ${ }^{60,61}$ In both the OIR and CNV models, PEDF overexpression attenuated the overexpression of inflammatory factors in the retina and eyecup in the OIR and CNV models, respectively. In cultured cells, PEDF suppressed the hypoxia-induced inflammatory factor expression in HRECs (see Supplemental Figure S2A at $h$ ttp://ajp.amjpathol.org). These results suggest that PEDF also plays an important role in regulation of inflammatory responses. Although PEDF has been suggested as antiangiogenic, antivasopermeability, and anti-inflammatory properties in the eye, ${ }^{4,7,62}$ the precise mechanism underlying its broad effects remains uncertain. Most importantly, previous evidence suggests that PEDF may exert its antiangiogenesis and anti-inflammatory activities via multiple pathways. Cai et al reported that PEDF inhibits phosphorylation of VEGF receptor-1 through increasing $\gamma$-secretase activity and inducing VEGF receptor-1 cleavage. ${ }^{63}$ In addition, Zhang et al showed that PEDF effectively inhibited VEGF via competing with VEGF for binding to the VEGF receptor. ${ }^{64}$ Recently, the overactivation of the canonical Wnt signaling pathway has been found to mediate retinal neovascularization, inflammation, and fibrosis in diabetic retinopathy. ${ }^{65-69}$ PEDF exerts its function through interactions with the Wnt pathway. However, the molecular mechanism by which PEDF regulates activity of VEGF and inflammatory cytokines in the eye remains to be elucidated.

In summary, this study established a transgenic model that ubiquitously overexpresses PEDF without any detectable defect in eye development or visual function. Furthermore, overexpression of PEDF attenuated pathological ocular neovascularization. The PEDF-Tg mice provide a useful model for studying the pathogenic mechanism for neovascularization in diabetic retinopathy, age-related macular degeneration and other neovascular disorders.

\section{Acknowledgment}

We thank Dr. Anne Murray for critical review of the manuscript.

\section{References}

1. Becerra SP, Sagasti A, Spinella P, Notario V: Pigment epitheliumderived factor behaves like a noninhibitory serpin: neurotrophic ac- tivity does not require the serpin reactive loop. J Biol Chem 1995, 270:25992-25999

2. Steele FR, Chader GJ, Johnson LV, Tombran-Tink J: Pigment epithelium-derived factor: neurotrophic activity and identification as a member of the serine protease inhibitor gene family. Proc Natl Acad Sci U S A 1993, 90:1526-1530

3. Becerra SP, Palmer I, Kumar A, Steele F, Shiloach J, Notario V, Chader GJ: Overexpression of fetal human pigment epithelium-derived factor in Escherichia coli: a functionally active neurotrophic factor. J Biol Chem 1993, 268:23148-23156

4. Dawson DW, Volpert OV, Gillis P, Crawford SE, Xu H, Benedict W, Bouck NP: Pigment epithelium-derived factor: a potent inhibitor of angiogenesis. Science 1999, 285:245-248

5. King GL, Suzuma K: Pigment-epithelium-derived factor-a key coordinator of retinal neuronal and vascular functions. N Engl J Med 2000 342:349-351

6. Amaral J, Fariss RN, Campos MM, Robison WG Jr, Kim H, Lutz R, Becerra SP: Transscleral-RPE permeability of PEDF and ovalbumin proteins: implications for subconjunctival protein delivery. Invest Ophthalmol Vis Sci 2005, 46:4383-4392

7. Zhang SX, Wang JJ, Gao G, Shao C, Mott R, Ma JX: Pigment epithelium-derived factor (PEDF) is an endogenous antiinflammatory factor. FASEB J 2006, 20:323-325

8. Matsuoka M, Ogata N, Otsuji T, Nishimura T, Takahashi K, Matsumura M: Expression of pigment epithelium derived factor and vascular endothelial growth factor in choroidal neovascular membranes and polypoidal choroidal vasculopathy. Br J Ophthalmol 2004, 88:809815

9. Filleur S, Nelius T, de Riese W, Kennedy RC: Characterization of PEDF: a multi-functional serpin family protein. J Cell Biochem 2009, 106:769-775

10. Yang $\mathrm{H}$, Grossniklaus HE: Constitutive overexpression of pigment epithelium-derived factor inhibition of ocular melanoma growth and metastasis. Invest Ophthalmol Vis Sci 2010, 51:28-34

11. Spranger J, Osterhoff M, Reimann M, Mohlig M, Ristow M, Francis MK, Cristofalo V, Hammes HP, Smith G, Boulton M, Pfeiffer AF: Loss of the antiangiogenic pigment epithelium-derived factor in patients with angiogenic eye disease. Diabetes 2001, 50:2641-2645

12. Holekamp NM, Bouck N, Volpert O: Pigment epithelium-derived factor is deficient in the vitreous of patients with choroidal neovascularization due to age-related macular degeneration. Am J Ophthalmol 2002, 134:220-227

13. Ogata N, Matsuoka M, Imaizumi M, Arichi M, Matsumura M: Decrease of pigment epithelium-derived factor in aqueous humor with increasing age. Am J Ophthalmol 2004, 137:935-936

14. Clements RS Jr, Robison WG Jr, Cohen MP: Anti-glycated albumin therapy ameliorates early retinal microvascular pathology in $\mathrm{db} / \mathrm{db}$ mice. J Diabetes Complications 1998, 12:28-33

15. Cohen MP, Hud E, Shea E, Shearman CW: Vitreous fluid of $\mathrm{db} / \mathrm{db}$ mice exhibits alterations in angiogenic and metabolic factors consistent with early diabetic retinopathy. Ophthalmic Res 2008, 40:5-9

16. Notari L, Miller A, Martinez A, Amaral J, Ju M, Robinson G, Smith LE, Becerra SP: Pigment epithelium-derived factor is a substrate for matrix metalloproteinase type 2 and type 9: implications for downregulation in hypoxia. Invest Ophthalmol Vis Sci 2005, 46:2736-2747

17. Mori K, Gehlbach P, Yamamoto S, Duh E, Zack DJ, Li Q, Berns KI, Raisler BJ, Hauswirth WW, Campochiaro PA: AAV-mediated gene transfer of pigment epithelium-derived factor inhibits choroidal neovascularization. Invest Ophthalmol Vis Sci 2002, 43:1994-2000

18. Stellmach V, Crawford SE, Zhou W, Bouck N: Prevention of ischemiainduced retinopathy by the natural ocular antiangiogenic agent pigment epithelium-derived factor. Proc Natl Acad Sci U S A 2001, 98:2593-2597

19. Raisler BJ, Berns KI, Grant MB, Beliaev D, Hauswirth WW: Adenoassociated virus type-2 expression of pigmented epithelium-derived factor or Kringles 1-3 of angiostatin reduce retinal neovascularization. Proc Natl Acad Sci U S A 2002, 99:8909-8914

20. Mori K, Gehlbach P, Ando A, McVey D, Wei L, Campochiaro PA: Regression of ocular neovascularization in response to increased expression of pigment epithelium-derived factor. Invest Ophthalmol Vis Sci 2002, 43:2428-2434

21. Huang Q, Wang S, Sorenson CM, Sheibani N: PEDF-deficient mice exhibit an enhanced rate of retinal vascular expansion and are more 
sensitive to hyperoxia-mediated vessel obliteration. Exp Eye Res 2008, 87:226-241

22. Park K, Chen Y, Hu Y, Mayo AS, Kompella UB, Longeras R, Ma JX: Nanoparticle-mediated expression of an angiogenic inhibitor ameliorates ischemia-induced retinal neovascularization and diabetes-induced retinal vascular leakage. Diabetes 2009, 58:19021913

23. Smith LE, Wesolowski E, McLellan A, Kostyk SK, D'Amato R, Sullivan R, D'Amore PA: Oxygen-induced retinopathy in the mouse. Invest Ophthalmol Vis Sci 1994, 35:101-111

24. Tobe T, Ortega S, Luna JD, Ozaki H, Okamoto N, Derevjanik NL, Vinores SA, Basilico C, Campochiaro PA: Targeted disruption of the FGF2 gene does not prevent choroidal neovascularization in a murine model. Am J Pathol 1998, 153:1641-1646

25. Mori K, Duh E, Gehlbach P, Ando A, Takahashi K, Pearlman J, Mori K, Yang HS, Zack DJ, Ettyreddy D, Brough DE, Wei LL, Campochiaro PA: Pigment epithelium-derived factor inhibits retinal and choroidal neovascularization. J Cell Physiol 2001, 188:253-263

26. Kachi S, Esumi N, Zack DJ, Campochiaro PA: Sustained expression after nonviral ocular gene transfer using mammalian promoters. Gene Ther 2006, 13:798-804

27. Hong DH, Pawlyk BS, Adamian M, Sandberg MA, Li T: A single, abbreviated RPGR-ORF15 variant reconstitutes RPGR function in vivo. Invest Ophthalmol Vis Sci 2005, 46:435-441

28. Chen J, Connor KM, Aderman CM, Smith LE: Erythropoietin deficiency decreases vascular stability in mice. J Clin Invest 2008, 118: $526-533$

29. Connor KM, Krah NM, Dennison RJ, Aderman CM, Chen J, Guerin KI, Sapieha P, Stahl A, Willett KL, Smith LE: Quantification of oxygeninduced retinopathy in the mouse: a model of vessel loss, vessel regrowth and pathological angiogenesis. Nat Protoc 2009, 4:15651573

30. Smith LE: Pathogenesis of retinopathy of prematurity. Acta Paediatr Suppl 2002, 91:26-28

31. Pe'er J, Folberg R, Itin A, Gnessin H, Hemo I, Keshet E: Upregulated expression of vascular endothelial growth factor in proliferative diabetic retinopathy. Br J Ophthalmol 1996, 80:241-245

32. Pierce EA, Avery RL, Foley ED, Aiello LP, Smith LE: Vascular endothelial growth factor/vascular permeability factor expression in a mouse model of retinal neovascularization. Proc Natl Acad Sci U S A 1995, 92:905-909

33. Miller JW, Adamis AP, Shima DT, D'Amore PA, Moulton RS, O'Reilly MS, Folkman J, Dvorak HF, Brown LF, Berse B: Vascular endothelia growth factor/vascular permeability factor is temporally and spatially correlated with ocular angiogenesis in a primate model. Am J Pathol 1994, 145:574-584

34. Ishibashi T, Hata Y, Yoshikawa H, Nakagawa K, Sueishi K, Inomata H: Expression of vascular endothelial growth factor in experimental choroidal neovascularization. Graefes Arch Clin Exp Ophthalmol 1997, 235:159-167

35. Kwak N, Okamoto N, Wood JM, Campochiaro PA: VEGF is major stimulator in model of choroidal neovascularization. Invest Ophthalmol Vis Sci 2000, 41:3158-3164

36. Hangai M, He S, Hoffmann S, Lim JI, Ryan SJ, Hinton DR: Sequential induction of angiogenic growth factors by TNF-alpha in choroidal endothelial cells. J Neuroimmunol 2006, 171:45-56

37. Bian ZM, Elner SG, Elner VM: Regulation of VEGF mRNA expression and protein secretion by TGF-beta2 in human retinal pigment epithelial cells. Exp Eye Res 2007, 84:812-822

38. Ambati J, Anand A, Fernandez S, Sakurai E, Lynn BC, Kuziel WA, Rollins BJ, Ambati BK: An animal model of age-related macular degeneration in senescent Ccl-2- or Ccr-2-deficient mice. Nat Med 2003, 9:1390-1397

39. Yamada K, Sakurai E, Itaya M, Yamasaki S, Ogura Y: Inhibition of laser-induced choroidal neovascularization by atorvastatin by downregulation of monocyte chemotactic protein-1 synthesis in mice. Invest Ophthalmol Vis Sci 2007, 48:1839-1843

40. Watanabe D, Takagi H, Suzuma K, Oh H, Ohashi H, Honda $Y$ : Expression of connective tissue growth factor and its potential role in choroidal neovascularization. Retina 2005, 25:911-918

41. Regatieri CV, Dreyfuss JL, Melo GB, Lavinsky D, Farah ME, Nader HB: Dual role of intravitreous infliximab in experimental choroidal neovascularization: effect on the expression of sulfated glycosaminoglycans. Invest Ophthalmol Vis Sci 2009, 50:5487-5494
42. Funatsu H, Yamashita H, Nakamura S, Mimura T, Eguchi S, Noma H, Hori S: Vitreous levels of pigment epithelium-derived factor and vascular endothelial growth factor are related to diabetic macular edema. Ophthalmology 2006, 113:294-301

43. Bhutto IA, McLeod DS, Hasegawa T, Kim SY, Merges C, Tong P, Lutty GA: Pigment epithelium-derived factor (PEDF) and vascular endothelial growth factor (VEGF) in aged human choroid and eyes with age-related macular degeneration. Exp Eye Res 2006, 82:99-110

44. Rasmussen H, Chu KW, Campochiaro P, Gehlbach PL, Haller JA, Handa JT, Nguyen QD, Sung JU: Clinical protocol: an open-label, phase I, single administration, dose-escalation study of ADGVPEDF 11D (ADPEDF) in neovascular age-related macular degeneration (AMD). Hum Gene Ther 2001, 12:2029-2032

45. Duh EJ, Yang HS, Suzuma I, Miyagi M, Youngman E, Mori K, Katai M, Yan L, Suzuma K, West K, Davarya S, Tong P, Gehlbach P, Pearlman J, Crabb JW, Aiello LP, Campochiaro PA, Zack DJ: Pigment epithelium-derived factor suppresses ischemia-induced retinal neovascularization and VEGF-induced migration and growth. Invest Ophthalmol Vis Sci 2002, 43:821-829

46. Ohno-Matsui K, Morita I, Tombran-Tink J, Mrazek D, Onodera M, Uetama T, Hayano M, Murota SI, Mochizuki M: Novel mechanism for age-related macular degeneration: an equilibrium shift between the angiogenesis factors VEGF and PEDF. J Cell Physiol 2001, 189:323-333

47. Gao G, Li Y, Zhang D, Gee S, Crosson C, Ma J: Unbalanced expression of VEGF and PEDF in ischemia-induced retinal neovascularization. FEBS Lett 2001, 489:270-276

48. Dot C, Parier V, Behar-Cohen F, Benezra D, Jonet L, Goldenberg B, Picard E, Camelo S, de Kozak Y, May F, Soubrane G, Jeanny JC: Influence of age on retinochoroidal healing processes after argon photocoagulation in C57bl/6j mice. Mol Vis 2009, 15:670-684

49. Kent D, Sheridan C: Choroidal neovascularization: a wound healing perspective. Mol Vis 2003, 9:747-755

50. Ogata N, Wada M, Otsuji T, Jo N, Tombran-Tink J, Matsumura M: Expression of pigment epithelium-derived factor in normal adult rat eye and experimental choroidal neovascularization. Invest Ophthalmol Vis Sci 2002, 43:1168-1175

51. Gehlbach P, Demetriades AM, Yamamoto S, Deering T, Duh EJ, Yang HS, Cingolani C, Lai H, Wei L, Campochiaro PA: Periocular injection of an adenoviral vector encoding pigment epithelium-derived factor inhibits choroidal neovascularization. Gene Ther 2003, 10:637-646

52. Okamoto N, Tobe T, Hackett SF, Ozaki H, Vinores MA, LaRochelle W, Zack DJ, Campochiaro PA: Transgenic mice with increased expression of vascular endothelial growth factor in the retina: a new model of intraretinal and subretinal neovascularization. Am J Pathol 1997, 151:281-291

53. Aiello LP, Avery RL, Arrigg PG, Keyt BA, Jampel HD, Shah ST, Pasquale LR, Thieme H, Iwamoto MA, Park JE, Nguyen HV, Aiello LM, Ferrara N, King GL: Vascular endothelial growth factor in ocular fluid of patients with diabetic retinopathy and other retinal disorders. N Engl J Med 1994, 331:1480-1487

54. Knudsen ST, Bek T, Poulsen PL, Hove MN, Rehling M, Mogensen CE: Macular edema reflects generalized vascular hyperpermeability in type 2 diabetic patients with retinopathy. Diabetes Care 2002, 25:2328-2334

55. Pelzek C, Lim JI: Diabetic macular edema: review and update. Ophthalmol Clin North Am 2002, 15:555-563

56. Ogata N, Nishikawa M, Nishimura T, Mitsuma Y, Matsumura M: Unbalanced vitreous levels of pigment epithelium-derived factor and vascular endothelial growth factor in diabetic retinopathy. Am J Ophthalmol 2002, 134:348-353

57. Boehm BO, Lang G, Feldmann B, Kurkhaus A, Rosinger S, Volpert O, Lang GK, Bouck N: Proliferative diabetic retinopathy is associated with a low level of the natural ocular anti-angiogenic agent pigment epithelium-derived factor (PEDF) in aqueous humor. A pilot study. Horm Metab Res 2003, 35:382-386

58. Aiello LP: Angiogenic pathways in diabetic retinopathy. N Engl J Med 2005, 353:839-841

59. Aiello LP, Gardner TW, King GL, Blankenship G, Cavallerano JD, Ferris FL 3rd, Klein R: Diabetic retinopathy. Diabetes Care 1998, 21:143-156

60. Shestakova MV, Kochemasova TV, Gorelysheva VA, Osipova TV, Polosukhina EP, Baryshnikov A, Dedov II: [The role of adhesion molecules (ICAM-1 and E-selectin) in development of diabetic microangiopathies]. Ter Arkh 2002, 74:24-27 
61. Clausen $P$, Jacobsen $P$, Rossing $K$, Jensen JS, Parving HH, FeldtRasmussen B: Plasma concentrations of VCAM-1 and ICAM-1 are elevated in patients with Type 1 diabetes mellitus with microalbuminuria and overt nephropathy. Diabet Med 2000, 17:644-649

62. Ueda S, Yamagishi SI, Okuda S: Anti-vasopermeability effects of PEDF in retinal-renal disorders. Curr Mol Med 10:279-283

63. Cai J, Jiang WG, Grant MB, Boulton M: Pigment epithelium-derived factor inhibits angiogenesis via regulated intracellular proteolysis of vascular endothelial growth factor receptor 1. J Biol Chem 2006, 281:3604-3613

64. Zhang SX, Wang JJ, Gao G, Parke K, Ma JX: Pigment epitheliumderived factor downregulates vascular endothelial growth factor (VEGF) expression and inhibits VEGF-VEGF receptor 2 binding in diabetic retinopathy. J Mol Endocrinol 2006, 37:1-12

65. Pulkkinen K, Murugan S, Vainio S: Wnt signaling in kidney development and disease. Organogenesis 2008, 4:55-59
66. Chen Y, Hu Y, Lu K, Flannery JG, Ma JX: Very low density lipoprotein receptor, a negative regulator of the wnt signaling pathway and choroidal neovascularization. J Biol Chem 2007, 282: 34420-34428

67. Chen Y, Hu Y, Zhou T, Zhou KK, Mott R, Wu M, Boulton M, Lyons TJ, Gao G, Ma JX: Activation of the Wnt pathway plays a pathogenic role in diabetic retinopathy in humans and animal models. Am J Pathol 2009, 175:2676-2685

68. Zhang B, Zhou KK, Ma JX: Inhibition of connective tissue growth factor overexpression in diabetic retinopathy by SERPINA3K via blocking the WNT/beta-catenin pathway. Diabetes 59:1809-1816

69. Zhou T, Hu Y, Chen Y, Zhou K, Zhang B, Gao G, Ma JX: The pathogenic role of the canonical Wnt pathway in age-related macular degeneration. Invest Ophthalmol Vis Sci 2010, 51:43714379 